\title{
Case Report: Intramedullary Cervical Spinal Cord Hemangioblastoma with an Evaluation of von Hippel-Lindau Disease
}

\author{
Steven Falowski MD \\ Thomas Jefferson University \\ Ashwini Sharan MD \\ Thomas Jefferson University \\ James S. Harrop MD \\ Thomas Jefferson University \\ John K. Ratliff MD \\ Thomas Jefferson University \\ Follow this and additional works at: https://jdc.jefferson.edu/jhnj \\ Part of the Neurology Commons \\ Let us know how access to this document benefits you
}

\section{Recommended Citation}

Falowski MD, Steven; Sharan MD, Ashwini; Harrop MD, James S.; and Ratliff MD, John K. (2008) "Case Report: Intramedullary Cervical Spinal Cord Hemangioblastoma with an Evaluation of von Hippel-Lindau Disease," JHN Journal: Vol. 4 : Iss. 2 , Article 4.

DOI: https://doi.org/10.29046/JHNJ.004.2.007

Available at: https://jdc.jefferson.edu/jhnj/vol4/iss2/4

This Article is brought to you for free and open access by the Jefferson Digital Commons. The Jefferson Digital Commons is a service of Thomas Jefferson University's Center for Teaching and Learning (CTL). The Commons is a showcase for Jefferson books and journals, peer-reviewed scholarly publications, unique historical collections from the University archives, and teaching tools. The Jefferson Digital Commons allows researchers and interested readers anywhere in the world to learn about and keep up to date with Jefferson scholarship. This article has been accepted for inclusion in JHN Journal by an authorized administrator of the Jefferson Digital Commons. For more information, please contact: JeffersonDigitalCommons@jefferson.edu. 


\section{Case Report: Intramedullary Cervical Spinal Cord Hemangioblastoma with an Evaluation of von Hippel-Lindau Disease}

\section{Steven Falowski MD, Ashwini Sharan MD, James S. Harrop MD, John K. Ratliff MD \\ Department of Neurological Surgery, Thomas Jefferson University, Philadelphia, Pennsylvania}

\section{History of Present IIIness}

MO is a 49 year old male with a history of multiple sclerosis who presents with a one year history of progressive numbness in his shoulders bilateral and upper back. The patient describes occasional sharp pains that radiate to his first three fingers on his right hand. He denies weakness, clumsiness, difficulty walking, or bladder/bowel dysfunction. He describes no problems with handwriting, or fine motor skills.

\section{Past Medical History}

Hypertension, Diverticulits, Multiple Sclerosis, optic neuritis

\begin{tabular}{ll}
\hline Past Surgical History & Inguinal hernia repair, Colectomy, Re-anastomosis of bowel \\
\hline Social History & Inguinal hernia repair, Colectomy, Re-anastomosis of bowel \\
\hline Allergies & NKDA \\
\hline Medications & Toprol, Beta Interferon \\
\hline Initial Neurological Exam & $\begin{array}{l}\text { The patient's exam was consistent with a decrease to light touch in } \\
\text { his bilateral lower extremities and right upper extremity. Pinprick } \\
\text { and proprioception were intact. Motor strength was 5/5 in all muscle } \\
\text { groups. There were no difficulties with tandem gait. Reflexes were 2+ } \\
\text { throughout and symmetric. The patient had showed neither } \\
\text { Babinski's nor Hoffman's sign. }\end{array}$ \\
\hline
\end{tabular}

\section{Hospital Course}

A MRI of the brain was performed early in the course of symptoms demonstrating his known multiple sclerosis lesions without any changes. With continued worsening symptoms, further workup included an MRI of the cervical spine which demonstrated a $1 \mathrm{~cm}$ homogenously enhancing intramedullary lesion at $\mathrm{C} 2$ with an associated cyst and syrinx.

Prior to surgical intervention, the patient was counseled on the risks entailed in the removal of a spinal cord tumor. Based on the characteristics on the MRI, a diagnosis of hemangioblastoma was favored and therefore the possibility of having von Hippel-Lindau (VHL) disease was discussed with the patient. The patient underwent an MRI of the complete neuro-axis including brain and spinal cord screening for any other lesions. An ultrasound of the abdomen was performed which demonstrated no renal lesions, liver lesions, or adrenal masses. An ophthalmologic examination demonstrated none of the stigmatisms associated with VHL.

Prior to surgical excision, an angiogram was performed for the potential to embolize any large vessels. However, no tumor blush was appreciated during the angiogram.

The patient underwent a laminectomy from C1-3 to expose the spinal cord. Intra-operative ultrasound was used to isolate the borders of the nodule and define the cystic component. A dural incision and midline myelotomy was performed. The tumor was removed en bloc and the cyst decompressed. The tumor was noted to be significantly vascular. Intra- operative ultrasound was utilized to confirm full resection. During removal of the tumor somatosensory evoked potentials were noted to decrease by approximately $50 \%$ in all four extremities.
The patient worked with physical therapy and was discharged home on post operative day number four. His post operative incisional pain was controlled with Percocet. The patient was also administered Valium and Neurontin to help with the neck pain and parasthesias following the surgery. The patient's neurological exam on discharge demonstrated mild numbness in the right upper extremity and slight weakness in right hand grip, with resolution of preoperative sensory deficits in the lower extremities. Motor exam was $5 / 5$ in all other muscle groups. Postoperative MRI demonstrated no residual tumor with expected post operative changes. Pathology was consistent with hemangioblastoma. In follow up the patients remaining right upper extremity numbness had resolved and the patient was able to return to work 8 weeks postoperatively.

\section{Discussion}

The decision to proceed with surgery was based on the natural history of this tumor. It may continue to grow and with further expanding of the syrinx or cystic cavity may produce further neurological deterioration. It can be anticipated that the best time for surgery would be while the patient has a strong neurological status and best chance for recovery.

Hemangioblastoma is a vascular neoplasm of the central nervous system. It is the most common primary neoplasm in the adult cerebellum, but is rarely a tumor of the spine ${ }^{1}$. Hemangioblastoma may occur sporadically or as a component of von Hippel-Lindau syndrome. Radiological findings such as associated cyst, an associated syrinx, and/or surrounding spinal cord reaction or edema ${ }^{2,3}$ are helpful in diagnosing hemangioblastoma. Thirty-two percent of patients with spinal hemangioblastoma have von Hippel-Lindau syndrome. Symptoms of spinal hemangioblastoma are similar to those of other spinal canal tumors and include sensory change, motor disturbance, and pain. Because the presentation of spinal hemangioblastoma is similar to that of other spinal canal masses, MRI studies can be useful in suggesting a diagnosis ${ }^{2}$.

VHL is a rare genetic condition. The disease is an autosomal dominant disorder carried on the third chromosome with near complete penetration and variable expression ${ }^{4}$. The gene behaves 


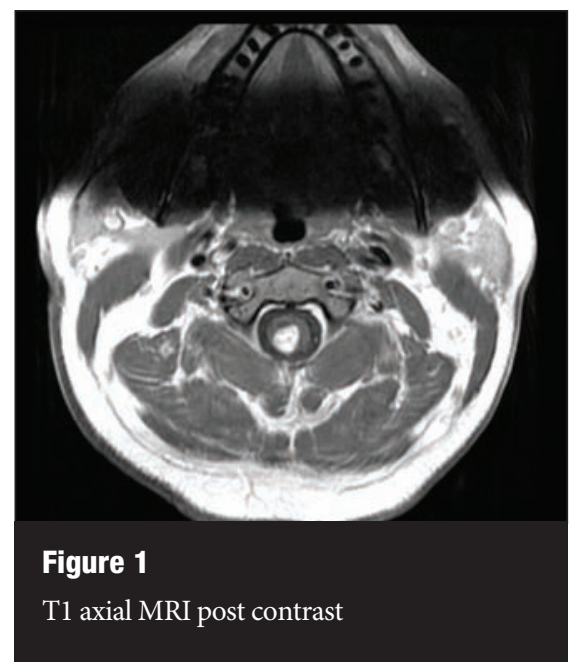

as a typical tumor suppressor gene. The age of onset, as well as severity is variable. There are various subtypes which characterize the risks of developing renal call carcinoma, pheochromocytoma, and angiomatosis. Angiomas are the most common presenting signs and symptoms of this disease syndrome. Of note, only $20 \%$ of patients with VHL develop pheochromocytomas.

Features of VHL can include hemangioblastoma's in the cerebellum and spinal cord, as well as angiomatosis in the retina and other organs. ${ }^{1}$ Other features include pheochromocytoma, renal cell and pancreatic cysts, renal cell carcinoma, as well as café au lait spots. Neurological sequeala and death arise from complications

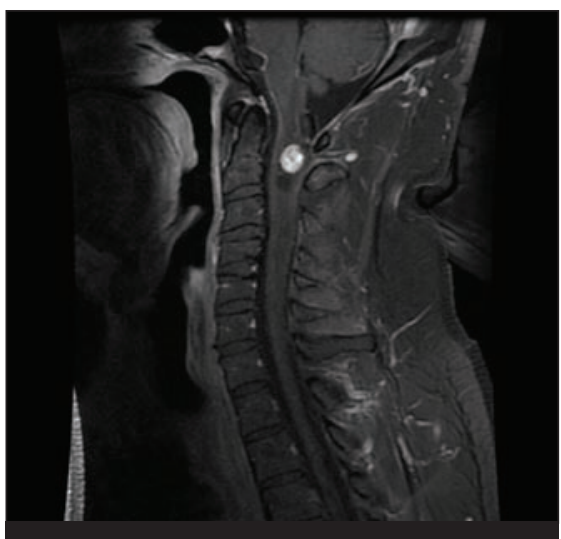

Figure 2

T1 sagittal MRI post contrast

associated with central nervous system tumors, as well as cardiovascular instability secondary to a pheochromocytoma. Decrease in visual acuity and blindness may arise as well ${ }^{5}$.

Work up for suspected VHL can include genetic studies, as well as Vanillylmandelic acid levels in urine. Imaging studies can include an MRI of the brain and spinal cord, ultrasound and/or CT of the abdomen, and ophthalmic exam with ocular dopplers 5 . VHL is usually a progressive disease and therapy should begin as soon as the diagnosis is made. Surgical treatment is usually indicated.

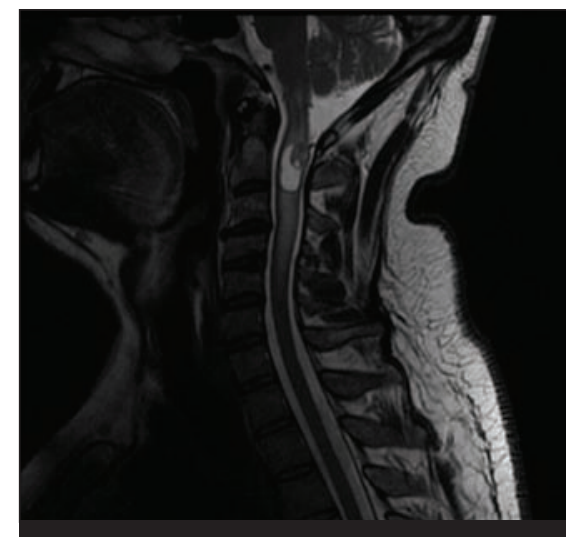

Figure 3

T2 sagittal MRI

\section{References:}

1. Huson SM, Harper PS, Hourihan MD, et al. Cerebellar haemangioblastoma and von Hippel-Lindau disease. Brain. Dec 1986;109 ( Pt 6):1297-310.

2. Browne TR, Adams RD, Robertson GH. Hemangioblastoma of the spinal cord. Arch Neurol 1976;33:435-441

3. Maher ER, Bentley E, Yates JR, et al. Mapping of von Hippel-Lindau disease to chromosome $3 \mathrm{p}$ confirmed by genetic linkage analysis. J Neurol Sci. Dec 1990;100(12):27-30.

4. Moore AJ. Ophthalmologic Screening of Von Hippel Lindau Disease. Eye. 1992;5:90-2.

5. Parizel PM, Baleriaux D, Rodesch G, et al. Gd-DTPA enhanced MR imaging of spinal tumors. AJNR 1989;10:249-258 